\title{
The impact of obesity on LADG for early gastric cancer
}

\author{
Ki-Han Kim¹, Min-Chan Kim¹, Ghap-Joong Jung ${ }^{1}$, and Hyung-Ho Kim² \\ ${ }^{1}$ Department of Surgery, Dong-A University College of Medicine, 3-1 Dongdaeshin-dong, Seo-gu, Busan 602-715, South Korea \\ ${ }^{2}$ Seoul National University Bundang Hospital, Gyeonggi-do, Korea
}

\begin{abstract}
Background. Laparoscopy-assisted distal gastrectomy (LADG) has become a viable alternative treatment for patients suffering with early gastric cancer. Surgeons have long thought that obesity might increase the rate of intraoperative or postoperative complications. We set out to clarify the effect that obesity has on performing LADG for the treatment of early gastric cancer.

Methods. We retrospectively reviewed 97 patients who had undergone LADG for early gastric cancer between May 1998 and March 2004. We measured the degree of obesity by using the body mass index (BMI; $\left.\mathrm{kg} / \mathrm{m}^{2}\right)$, and we compared the surgical outcomes between the normal BMI group (BMI < $23 \mathrm{~kg} / \mathrm{m}^{2}$ ) and the high BMI group $\left(\right.$ BMI $\left.\geq 23 \mathrm{~kg} / \mathrm{m}^{2}\right)$. We further subdivided the patients into four groups: normal BMI males and normal BMI females, and high BMI males and high BMI females, and we analyzed them in terms of operation times, numbers of retrieved lymph nodes, and rates of postoperative complications.

Results. There were no significant differences between the normal and high BMI groups in terms of the patients' characteristics, surgical outcomes, postoperative courses, postoperative complications, and operation times. There were no statistically significant differences in the number of retrieved lymph nodes or in the rate of postoperative complications among the four groups $(P=0.5030$ and $P=0.3489$, respectively). However, there was a statistically significant difference in operation times among the four groups $(P=0.004)$. Specifically, the males in the high BMI group required a longer operation time than did the females with a normal BMI $(P=0.006)$ and the females with a high BMI $(P=0.019)$.

Conclusions. For LADG in patients with early gastric cancer, obesity may affect the operation time, and men with high BMI require a longer operation time than do women with normal or high BMI.
\end{abstract}

Key words Early gastric cancer · Laparoscopy · Obesity · Body mass index

Offprint requests to: M.-C. Kim

Received: February 8, 2006 / Accepted: July 31, 2006

\section{Introduction}

Although the incidence of gastric cancer has been declining in Western countries [1], recent data have shown that worldwide, it is both the fourth most common cancer and the second most common cause of cancer death [2]. The incidence of early gastric cancer in Korea has been increasing because of recent improvements in early diagnosis [3]. Many studies have focused on improving the quality of life and achieving an early recovery after operation by performing minimally invasive surgery instead of open surgery for treating early gastric cancer [4-7]. Gastric surgeons have displayed great interest in laparoscopic surgery for early gastric cancer because laparoscopic surgery has many advantages over conventional open surgery in terms of the patients' quality of life [4-7]. We have reported a comparative study of laparoscopic surgery and conventional open surgery for gastric cancer [7], and a number of authors have recently presented their experiences with laparoscopic surgery for the treatment of early gastric cancer $[4,7,8]$.

Surgeons have long thought that obesity might increase the rate of intraoperative or postoperative complications $[9,10]$. A recent report from Japan concluded that a higher BMI hampered the performance of lymphadenectomy during gastric cancer surgery, and a higher BMI was reported as an independent predictor of cancer recurrence [11]. However, there are only a few studies of the relationship between obesity and laparoscopy-assisted radical gastrectomy. In this study, we set out to clarify the effects of obesity on LADG for treating early gastric cancer.

\section{Patients, materials, and methods}

We retrospectively reviewed 97 patients who had undergone LADG with systemic lymphadenectomy for 
treating early gastric cancer, between May 1998 and March 2004; we used the records from the Stomach Cancer Database of Dong-A University Hospital. All the operations were performed by two surgeons, and the operative technique that was used has been described previously [12]. For these patients, the distal two-thirds of the stomach was resected using a stapler. Billroth I gastroduodenostomy was performed using a circular stapler, and Billroth II gastrojejunostomy, with side-to-side jejunojejunostomy, was performed using two endoscopic stapling devices or by hand suturing. We excluded those patients who had undergone laparoscopy-assisted proximal gastrectomy or total gastrectomy and also those patients with mucosal lesions that were more suitable for endoscopic mucosal resection (EMR). We also excluded patients with a history of upper abdominal surgery. The indications used at out hospital for EMR were a Tm lesion with a size less than $2 \mathrm{~cm}$ and no ulcer present.

We measured the degree of obesity by using the body mass index (BMI; $\mathrm{kg} / \mathrm{m}^{2}$ ), and we assigned the patients to two groups: those with a normal BMI (BMI $<23 \mathrm{~kg}$ / $\mathrm{m}^{2}$ ), and those with a high BMI (BMI $\left.\geq 23 \mathrm{~kg} / \mathrm{m}^{2}\right)$, according to the World Health Organization Western Pacific Region The Asia-Pacific Perspective: redefining obesity and its treatment [13]. We reviewed the two groups in terms of the patients' characteristics, surgical outcomes, postoperative courses, and postoperative complications, and operation times. We also subdivided the two groups into four groups according to sex to analyze differences in the operation times, numbers of retrieved lymph nodes, and the incidence of postoperative complications.

Statistical analysis was performed using the statistical package SPSS for Windows, version 12.0 (SPSS, Chicago, IL, USA). The results were interpreted by means of the unpaired Student's $t$ test, the $\chi^{2}$ test, and the oneway analysis of variance (ANOVA) test. $P$ values of less than 0.05 were considered statistically significant. All values were expressed as means \pm SDs.

\section{Results}

The average BMI of all the patients was $23.03 \mathrm{~kg} / \mathrm{m}^{2}$ (range, $17.51-29.32 \mathrm{~km} / \mathrm{m}^{2}$ ). The normal BMI group consisted of 52 patients ( 29 males and 23 females), and the high BMI group consisted of 45 patients (25 males and 20 females). There were no significant differences between the two groups in terms of the patients' characteristics or the pathologic results (Table 1).

The mean operation time in the normal BMI group was $244.8 \pm 35.5 \mathrm{~min}$ (range, $180.0-330.0 \mathrm{~min}$ ); the mean operation time in the high BMI group was $260 \pm 52.3 \mathrm{~min}$ (range, $150.0-415.0 \mathrm{~min}$ ), and there were no statistically significant differences between these two groups $(P=0.0892$; Table 2$)$. The mean operation times for the four subgroups (the high BMI male group, the normal BMI male group, the high BMI

Table 1. Patients' characteristics

\begin{tabular}{|c|c|c|c|}
\hline & High BMI $(n=45)$ & Normal BMI $(n=52)$ & $P$ value \\
\hline BMI $\left(\mathrm{kg} / \mathrm{m}^{2}\right.$, mean $\left.\pm \mathrm{SD}\right)$ (range) & $25.3 \pm 1.8(23.05-29.32)$ & $21.0 \pm 1.3(17.51-22.94)$ & $<0.0001$ \\
\hline Age $($ mean $\pm S D)$ & $55 \pm 11$ & $56 \pm 12$ & 0.5728 \\
\hline Sex (male/female) & $25 / 20$ & $29 / 23$ & 1.0000 \\
\hline Comorbidity (\%) & $8(17.8 \%)$ & $5(9.6 \%)$ & 0.3707 \\
\hline Depth of tumor invasion $(\mathrm{m} / \mathrm{sm})$ & $25 / 20$ & $39 / 13$ & 0.0545 \\
\hline Number of retrieved LN $($ mean $\pm S D)$ & $23 \pm 10$ & $23 \pm 11$ & 0.9831 \\
\hline LN metastasis & 3 & 4 & 1.0000 \\
\hline Extent of lymph node dissection & & & 0.6853 \\
\hline $\mathrm{D} 1+\alpha$ & 8 & 8 & \\
\hline $\mathrm{D} 1+\beta$ & 29 & 31 & \\
\hline D2 & 8 & 13 & \\
\hline
\end{tabular}

m, mucosa; sm, submucosa; LN, lymph node; BMI, body mass index

Table 2. Surgical outcomes and postoperative courses

\begin{tabular}{|c|c|c|c|}
\hline & High BMI $(n=45)$ & Normal BMI $(n=52)$ & $P$ value \\
\hline Operation time (min; mean $\pm \mathrm{SD})$ (range) & $260.2 \pm 52.3(150.0-415.0)$ & $244.8 \pm 35.5(180.0-330.0)$ & 0.0892 \\
\hline Number of patients transfused (\%) & $5(11.1 \%)$ & $13(25.0 \%)$ & 0.1157 \\
\hline Time to first flatus (days; mean \pm SD) & $3.5 \pm 1.2$ & $3.6 \pm 1.2$ & 0.5397 \\
\hline Postoperative WBC count $\left(10^{3} / \mathrm{mm}^{2} ;\right.$ mean $\left.\pm \mathrm{SD}\right)$ & $11.3 \pm 4.3$ & $12.4 \pm 3.8$ & 0.1742 \\
\hline Postoperative hospital stay (days; mean \pm SD) & $8.7 \pm 4.3$ & $10.2 \pm 6.0$ & 0.1870 \\
\hline
\end{tabular}

LN, lymph node; BMI, body mass index 
female group, and the normal BMI female group) were $277.2 \pm 52.7,252.1 \pm 34.3,239.0 \pm 44.4$, and $235.7 \pm$ $35.6 \mathrm{~min}$, respectively. The mean numbers of retrieved lymph nodes in the four subgroups were 22.4, 24.9, 23.5 , and 20.4, respectively; postoperative complications occurred in one six, three, and four patients, respectively. When we retrospectively analyzed these values by means of one-way ANOVA and $\chi^{2}$ testing, there were no statistically significant differences among the four subgroups in the number of retrieved lymph nodes or in the rate of postoperative complication $(P=0.5030$ and $P=0.3489$, respectively). However, there were statistically significant differences in operation times among the four subgroups $(P=0.004)$. The male patients with high BMIs required a significantly longer operation time than did the female groups with normal and high BMIs ( $P=0.006$ and $P=0.019$, respectively; Fig. 1).

The number of patients requiring transfusion, the time interval to first flatus, the postoperative leukocyte count, the postoperative hospital stay, and the rate of postoperative complications in the high and normal BMI groups showed no statistically significant differences (Tables 2 and 3).

\section{Discussion}

Surgeons have generally thought that obesity might possibly increase the incidences of intraoperative and/ or postoperative anesthetic complications [14], intraoperative bleeding, and surgical complications, and it is also thought that obesity may increase operation times and the risk of cardiopulmonary diseases $[9,10]$. Some studies have reported the effect of obesity on open gastric cancer surgery. The Japanese studies by Inagawa et al. [15] and Dhar et al. [11] have shown that obesity may cause an increased rate of postoperative complications and a poor prognosis. In contrast, other studies, done in Europe by Gretschel et al. [16] and Barry et al. [17], have shown that obesity does not affect postoperative complications, nor does it lead to a poor prognosis. Many surgeons have viewed obesity as a contraindication for abdominal laparoscopic surgery, because of the difficulty it creates for entering the abdominal cavity and also because of the limited visualization of the surgical field [18]. However, for laparoscopic surgery of other organs, it has been reported that the incidence of operative and postoperative complications, the amount of operative blood loss, the operation time, and the

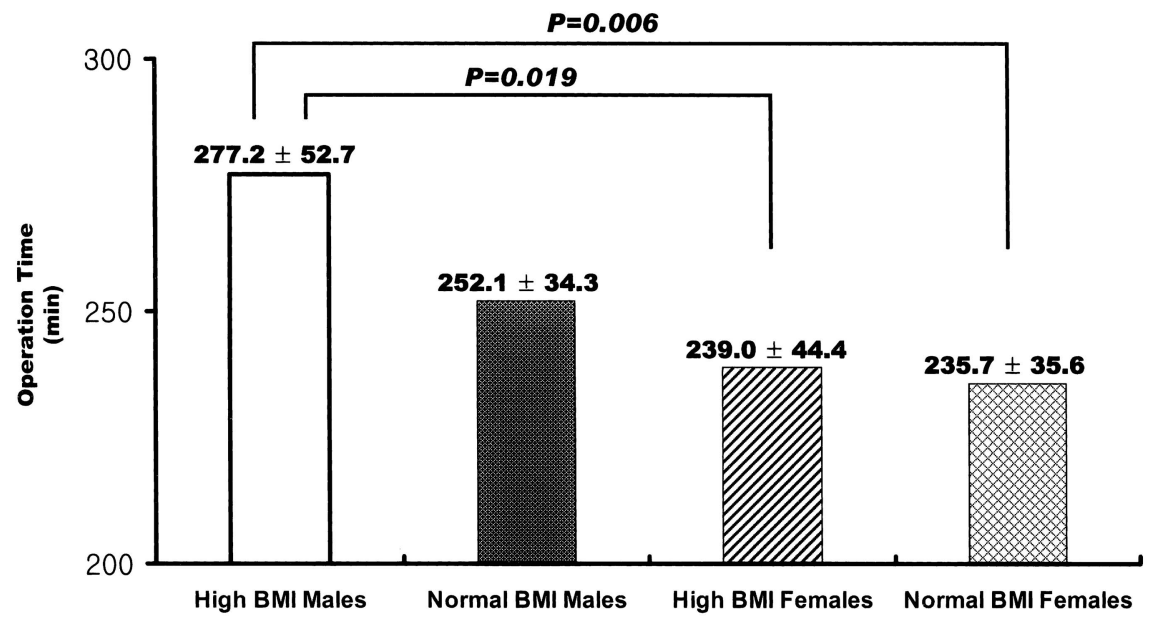

Fig. 1. Mean operation times. There were statistically significant differences among the four groups (one-way analysis of variance [ANOVA] test; $P=0.004)$. $B M I$, body mass index.

Table 3. Postoperative complications

\begin{tabular}{lccr}
\hline & High BMI $(n=45)$ & Normal BMI $(n=52)$ & $P$ value \\
\hline Total $(\%)$ & $4(8.9 \%)$ & $10(19.2 \%)$ & 0.0815 \\
Anastomosis bleeding & 2 & 4 & \\
Duodenal stump leakage & 0 & 1 & \\
Intraabdominal abscess & 0 & 1 & \\
Spleen infarction & 0 & 1 & \\
Wound infection & 1 & 1 & \\
Wound seroma & 1 & 0 & \\
Dumping syndrome & 0 & 1 & \\
Pleural effusion & 0 & 1 &
\end{tabular}

BMI, body mass index 
length of the hospital stay were similar in obese and nonobese patients who underwent laparoscopic surgery [19-23].

Gynecological research has shown that laparoscopic surgery for gynecological maladies was safe and feasible for women with high BMIs [19], and they could be safely managed via laparoscopy, with excellent surgical outcomes, short hospitalizations, and less postoperative pain than with open procedures [20]. Morbid obesity was originally considered as a contraindication for laparoscopic cholecystectomy [21]. However, surgeons now have much more experience with minimally invasive surgery and this has changed the old concept. Laparoscopic cholecystectomy has recently been proposed as the best approach for gallbladder removal in morbidly obese patients [22]. Likewise, two reviews of laparoscopic appendectomy [23], which compared the traditional open method with the laparoscopic approach, have shown that obesity did not increase the complication rates in the laparoscopic group, and, rather surprisingly, this finding suggested that obesity may actually be an indication for minimally invasive surgery.

In 1991, Kitano et al. [8] performed the first laparoscopy-assisted distal gastrectomy for treating early gastric cancer, and since then many gastric surgeons have presented their results for laparoscopic surgery for early gastric cancer. However, not many studies have examined the relationship between obesity and laparoscopy-assisted radical gastrectomy. In the present study, the average BMI of the enrolled patients was $23.03 \mathrm{~kg} / \mathrm{m}^{2}$. According to the guidelines of the World Health Organization [13], we assigned our patients to two groups: those with a normal BMI $\left(\mathrm{BMI}<23 \mathrm{~kg} / \mathrm{m}^{2}\right)$ and those with a high $\mathrm{BMI}\left(\mathrm{BMI} \geq 23 \mathrm{~kg} / \mathrm{m}^{2}\right)$. Noshiro et al. [24] have shown that LADG for heavier patients was associated with more technical difficulties and the disadvantages of a longer operation time and delayed recovery of bowel activity, compared with findings in normal-weight patients. In the report of Yasuda et al. [25], the operation time was longer in the obese group, but no differences were found in the other operative parameters. Our study showed that there were no statistically significant differences between our two BMI groups in age, sex, depth of tumor invasion, lymph node metastasis, operation time, postoperative leukocyte count, number of patients requiring transfusion, the time interval to first flatus, the postoperative hospital stay, and the postoperative complications. However, when we analyzed the values for mean operation time, the number of retrieved lymph nodes, and the rate of postoperative complications among the four groups subdivided by sex, the number of retrieved lymph nodes and the rate of postoperative complications showed no statistically significant differences among the four groups, but there was a statistically significant differ- ence in the mean operation time among these four groups. As mentioned previously, this finding suggests that the BMI of patients does not affect the incidence of postoperative complications or the performance of radical lymphadenectomy for early gastric cancer. However, in regard to operation time, the procedure took significantly longer in the male patients with a high BMI than in it did in either of the female groups. In our study, we found no significant difference in the operation times between the normal and high BMI groups, and this is in contrast to the results of Noshiro et al. [24]. We interpret this difference as possibly being due to the very low proportion of female patients in Noshiro's high BMI group (18:1), as compared with our high BMI group $(25: 20)$. One reason we should take obesity into practical account for LADG may be that this procedure is quite different from the other laparoscopic procedures, in that LADG is a radical operation that requires systemic lymphadenectomy. During LADG, the fat tissue of the intraabdominal cavity may hinder surgeons from performing extensive lymphadenectomy. Generally, the body fat distribution in males tends to accumulate in the intraabdominal area more than in the subcutaneous area, and this is in contrast to the fat distribution generally seen in females. ${ }^{26}$ In this sense, the longer operation time for heavier male patients may be explicable, because the greater amount of abdominal fat allows surgeons a poorer view of the operative field, less room for surgical manipulation, and more difficultly in detecting blood vessels that are hidden in the massive adipose tissue of the mesenterium and omentum. The massive and fragile adipose tissue can be easily torn, even by gentle traction, and it bleeds easily, and this further results in a poor view of the surgical field and more difficulty in achieving precision of the complete procedure [27].

In the present study, we found that there was no difference between the high and normal BMI patients in the extent of lymphadenectomy or in the number of lymph nodes retrieved, but the operation took a longer time in the male patient with a high BMI, due to the technical difficulty that resulted from the high fat content in the peritoneal cavity.

\section{Conclusions}

Surgeons should be aware that male patients with a high BMI will need a longer operation time during LADG, yet LADG is still a technically feasible and acceptable method for obese patients suffering with early gastric cancer. Special attention should be paid to the patient's BMI when surgeons plan to perform LADG for patients with a heavier body weight, especially for obese male patients. 


\section{References}

1. Devesa SS, Blot WJ, Fraumeni JF Jr. Changing patterns in the incidence of esophageal and gastric carcinoma in the United States. Cancer 1998:83:2049-53.

2. Parkin DM, Bray FI, Devesa SS. Cancer burden in the year 2000. The global picture. Eur J Cancer 2001;37(Suppl 8):4-66.

3. Min YI. Epidemiology and pathogenesis of stomach cancer. Korean J Med 1998;55:474-80.

4. Adachi Y, Shiraishi N, Shiromizu A, Bandoh T, Aramaki M, Kitano S. Laparoscopy-assisted Billroth I gastrectomy compared with conventional open gastrectomy. Arch Surg 2000;135:806-10.

5. Shimizu S, Uchiyama A, Mizumoto K, Morisaki T, Nakamura K, Shimura $\mathrm{H}$, et al. Laparoscopically assisted distal gastrectomy for early gastric cancer: is it superior to open surgery? Surg Endosc 2000;14:27-31.

6. Huscher CG, Mingoli A, Sgarzini G, Sansonetti A, Di Paola M, Recher A, et al. Laparoscopic versus open subtotal gastrectomy for distal gastric cancer: 5-year results of a randomized prospective trial. Ann Surg 2005;241:232-7.

7. Kim MC, Kim KH, Kim HH, Jung GJ. Comparison of laparoscopy-assisted by conventional open distal gastrectomy and extraperigastric lymph node dissection in early gastric cancer. J Surg Oncol 2005;91:90-4.

8. Kitano S, Shiraishi N, Kakisako K, Yasuda K, Inomata M, Adachi Y. Laparoscopy-assisted Billroth-I gastrectomy (LADG) for cancer: our 10 years' experience. Surg Laparosc Endosc Percutan Tech 2002;12:204-7.

9. Holub Z, Jabor A, Kliment L, Fischlova D, Wagnerova M. Laparoscopic hysterectomy in obese women: a clinical prospective study. Eur J Obstet Gynecol Reprod Biol 2001;98:77-82.

10. Pikarsky AJ, Saida Y, Yamaguchi T, Martinez S, Chen W, Weiss EG, et al. Is obesity a high-risk factor for laparoscopic colorectal surgery? Surg Endosc 2002;16:855-8.

11. Dhar DK, Kubota H, Tachibana M, Kotoh T, Tabara H, Masunaga R, et al. Body mass index determines the success of lymph node dissection and predicts the outcomes of gastric carcinoma patients. Oncology 2000;59:18-23.

12. Kim MC, Kim HH, Jung GJ. Surgical outcome of laparoscopyassisted gastrectomy with extraperigastric lymph node dissection for gastric cancer. Eur J Surg Oncol 2005;31:420-3.

13. World Health Organization Western Pacific Region. The AsiaPacific perspective; redefining obesity and its treatment. WHO; 2000. pp. $17-8$.
14. Adams JP, Murphy PG. Obesity in anaesthesia and intensive care. Br J Anaesth 2000;85:91-108.

15. Inagawa S, Adachi S, Oda T, Kawamoto T, Koike N, Fukao K. Effect of the fat volume on postoperative complications and survival rate after D2 dissection for gastric cancer. Gastric Cancer 2000;3:141-4.

16. Gretschel S, Christoph F, Bembenek A, Estevez-Schwarz L, Schneider U, Schlag PM. Body mass index does not affect systematic D2 lymph node dissection and postoperative morbidity in gastric cancer patients. Ann Surg Oncol 2003;10:363-8.

17. Barry JD, Blackshaw GR, Edwards P, Lewis WG, Murphy P, Hodzovic I, et al. Western body mass indices need not compromise outcomes after modified D2 gastrectomy for carcinoma. Gastric Cancer 2003;6:80-5.

18. Loffer FD, Pent D. Laparoscopy in the obese patient. Am J Obstet Gynecol 1976;125:104-7.

19. Eltabbakh GH, Piver MS, Hempling RE, Recio FO. Laparoscopic surgery in obese women. Obstet Gynecol 1999;94:704-8.

20. Eltabbakh GH, Shamonki MI, Moody JM, Garafano LL. Hysterectomy for obese women with endometrial cancer: laparoscopy or laparotomy? Gynecol Oncol 2000;78:329-35.

21. Gadacz TR, Talamini MA Traditional versus laparoscopic cholecystectomy. Am J Surg 1991;161:336-8.

22. Phillips EH, Carroll BJ, Fallas MJ, Pearlstein AR. Comparison of laparoscopic cholecystectomy in obese and non-obese patients. Am Surg 1994;60:316-21.

23. Jitea N, Angelescu N, Burcos T, Cristian D, Voiculescu S, Mircea N. Laparoscopic appendectomy in obese patients. A comparative study with open appendectomy. Chirurgia (Bucur) 1996;45:203-5.

24. Noshiro H, Shimizu S, Nagai E, Ohuchida K, Tanaka M. Laparoscopy-assisted distal gastrectomy for early gastric cancer: is it beneficial for patients of heavier weight? Ann Surg 2003;238: 680-5.

25. Yasuda K, Inomata M, Shiraishi N, Izumi K, Ishikawa K, Kitano S. Laparoscopy-assisted distal gastrectomy for early gastric cancer in obese and nonobese patients. Surg Endosc 2004;18:1253-6.

26. Larson DE, Hunter GR, Williams MJ, Kekes-Szabo T, Nyikos I, Goran MI. Dietary fat in relation to body fat and intraabdominal adipose tissue: a cross-sectional analysis. Am J Clin Nutr 1996;64: 677-84.

27. Moriwaki Y, Kunisaki C, Kobayashi S, Harada H, Imai S, Kasaoka C. Does body mass index (BMI) influence morbidity and long-term survival in gastric cancer patients after gastrectomy? Hepatogastroenterology 2003;50:284-8. 